\title{
Ionospheric Response to Solar Wind Pressure Pulses Under Northward IMF Conditions
}

\author{
Kan Liou ${ }^{1, *}$, Desheng Han ${ }^{2}$, and Huigen Yang ${ }^{2}$ \\ ${ }^{1}$ The Johns Hopkins University Applied Physics Laboratory, Laurel, Maryland, USA \\ ${ }^{2}$ Polar Research Institute of China, Pudong, Shanghai, PRC, China
}

Received 23 January 2012, accepted 11 September 2012

\begin{abstract}
Enhancements of aurora and auroral electrojets in response to sudden compression of the magnetosphere by shocks/ pressure pulses are well known and have been attributed by some to compression-enhanced magnetic field reconnection. To examine such a view, we analyze a fortuitous event that is comprised of a series of pressure pulses $(<20 \mathrm{~min})$ on November 8,2000 . These pressure pulses were preceded by a large, northward interplanetary magnetic field (IMF) that lasted more than 15 hours such that effects from reconnection can be minimized. Auroral images acquired by ultraviolet imager on board the Polar satellite clearly show intensifications of the aurora that occurred first near local noon and progressively extended from dayside to nightside. The area-integrated global auroral power reached $\sim 30$ gigawatts $(\mathrm{GW})$. It is also found that the global auroral power is well correlated with the solar wind dynamic pressure (correlation coefficient $r \sim 0.90$ ), rather than the change in the solar wind dynamic pressure. In-situ measurements of particle data from the Defense Meteorological Satellite Program satellite indicate that the magnetospheric source for the pressure-enhanced auroras is most likely the central plasma sheet. Other ionospheric parameters such as the auroral electrojet $(A E$ index $)$, magnetic storm index $(S y m-H)$, and the cross polarcap potential drop also show a one-to-one correspondence to the pressure pulses. In one instance the auroral electrojets $A E$ index reached more than $200 \mathrm{nT}$, the cross polar-cap potential drop $\left(\phi_{p c}\right)$ inferred from the SuperDARN radar network ionospheric plasma convection increased to $\sim 60 \mathrm{kV}$. The observed increases in the auroral emissions, $A E$, and polar cap potential were not associated with substorms. Our result strongly suggests that solar wind pressure pulses are an important source of geomagnetic activity during northward IMF periods.
\end{abstract}

Key words: Particle precipitation, Auroral ionosphere, Solar wind-magnetosphere interactions

Citation: Liou, K., D. Han, and H. Yang, 2013: Ionospheric response to solar wind pressure pulses under northward IMF conditions. Terr. Atmos. Ocean. Sci., 24, 183-195, doi: 10.3319/TAO.2012.09.11.01(SEC)

\section{INTRODUCTION}

The response of the magnetosphere-ionosphere system to variations in the solar wind plasma and interplanetary magnetic field (IMF) constitutes a fundamental element in magnetospheric physics. Magnetic field merging (Dungey 1961) and viscous interaction (Axford and Hines 1961) are two well recognized processes that permit the transfer of mass, momentum, and energy of solar wind into the magnetosphere. Magnetic field merging permits a direct entry of solar wind plasma and electric field through the newly opened Earth's magnetic field, while viscous interaction allows transfer of solar wind mass and momentum diffusively

\footnotetext{
* Corresponding author

E-mail:kan.liou@jhuapl.edu
}

across the magnetosphere boundary layers. Although the energy density of the IMF is small in comparison with that of the solar wind plasma, the southward component of the IMF, which enhances the coupling, perhaps through merging, is recognized as a primary cause of geomagnetic and auroral activity (cf., Newell et al. 2007). Statistical analysis has shown that the southward component of the IMF is the major parameter responsible for the most enhanced aurora observed, with some delay, in the premidnight sector (Liou et al. 1998). An approximately linear relationship has also been found to exist between the solar wind speed and the nightside auroral power regardless of the sign of the IMF $B_{z}$, and the effect of solar wind speed probably plays the dominant role at times during northward IMF conditions (Liou et al. 1998). 
Although evidence of global auroral intensification after magnetospheric compression by shocks was first reported 25 years ago (Craven et al. 1986), significance of sudden changes in the solar wind dynamic pressure on the dynamics of the magnetosphere-ionosphere system was not widely recognized until the International Solar-Terrestrial Physics (ISTP) Program era when large amount of global auroral images became available. The intensive studies of the 6 - 11 January 1997, coronal mass ejection (CME)/magnetic cloud (MC) event clearly demonstrated global auroral enhancements associated with the crossing of interplanetary shocks and pressure pulses (e.g., Spann et al. 1998; Zhou and Tsurutani 1999; Tsurutani et al. 2001). The impingement of a sudden increase in the solar wind dynamic pressure on the Earth's magnetosphere produces auroral brightenings first on the dayside around the local noon. The initial brightening is localized and the region of brightening often extends quickly antisunward to cover a much wider local-time sector of the oval. The effect of magnetospheric compression is not limited to the dayside auroral oval; compression of the magnetosphere by shocks can also enhance auroral activity in the nighttime sector (Zhou and Tsurutani 2001; Boudouridis et al. 2003; Liou et al. 2003), widen the auroral zone width, and reduce the polar cap size (Boudouridis et al. 2003, 2004). Furthermore, Liou et al. (2006) demonstrated that global auroral responses to negative pressure pulses (magnetospheric decompression) are opposite to that of positive pressure pulses (i.e., decompression of the magnetosphere quenches the global development of auroras). These study results strongly suggest that interplanetary shocks/pressure pulses can be an important source of solar wind energy transfer to the magnetosphere creating geomagnetic and auroral activity.

The effect of magnetospheric compression on geomagnetic and auroral activity depends on the sign of IMF $B_{z}$. Previous study results suggest that the compression effect is more pronounced during southward than during northward IMF conditions (e.g., Liou et al. 1998; Zhou and Tsurutani 2001; Boudouridis et al. 2003, 2005). These works suggest that enhanced solar wind-magnetosphere coupling occurs after a sudden increase in dynamic pressure under a southward IMF. Boudouridis et al. $(2004,2007)$ attributed the effect to the enhancement of dayside reconnection resulting from a solar wind dynamic pressure. A valid question is whether or not the compression effect still exists when the magnetosphere is extremely quiet. To address this question, we have identified a fortuitous event involving a series of large pressure pulses over an extended period (more than 12 hours) of strongly northward IMF to minimize the effects of magnetic reconnection. While viscous interactions still exist during northward IMF, the typical efficiency of solar wind energy injection into the magnetosphere is estimated 30 - 100 times less than during periods of southward IMFs (Tsurutani and Gonzalez 1995; Du et al. 2011). We per- form analysis of the responses of a number of ionospheric parameters to the pressure pulses to provide a quantitative measure of the compression effect. We also study the magnetospheric source and provide a possible mechanism for the compression aurora.

\section{OBSERVATIONS}

\subsection{Solar Wind and Geomagnetic Conditions}

This special event occurred from 0200 to 1200 UT on November 8, 2000. According to the solar wind plasma data acquired from the Solar Wind Experiment (SWE) instrument (Ogilvie et al. 1995) and the magnetic field data acquired from the Magnetic Field Investigation (MFI) instrument (Lepping et al. 1995) on board the Wind spacecraft, which was in the solar wind $\sim 70-80 R_{E}$ upstream of the Earth, a magnetic cloud (from 2200 UT, November 6 to 1800 UT, November 7) preceded the event by several hours [see, e.g., Fig. 2 of Nieves-Chinchilla and Viñas (2008)]. Inside the cloud the magnetic field was large and southward ( -10 nT) initially. After $\sim 1200$ UT, November 7, the magnetic field smoothly turned northward into the second half of the cloud and remained large $(\sim 15 \mathrm{nT})$ for more than 18 hours. After the passage of the cloud, Wind observed a number of shortlived pressure pulses on November 8. All these pressure pulses were caused by density changes (solar wind velocity showed little changes) and were associated with an increase in the thermal temperature and a decrease in the magnetic field (magnetic cavities).

A large negative IMF $B_{z}$ component in the magnetic cloud front sheath initiated a large magnetic storm $\left(D_{s t}<\right.$ $-160 \mathrm{nT}$ ), which subsided several hours before the start of the event. The planetary $K_{P}$ index was 2 for the six-hour period prior to the start of the event ( $\sim 200$ UT on November 8,2000 ) and increased to 5 - in three hours after the arrival of the pressure pulses/magnetic cavities on the Earth. These solar wind structures also produced two large positive deflections in $D_{s t}$. Positive excursions in $D_{s t}$ at times of high solar wind dynamic pressures are well known and are caused by the increase in the magnetopause current and the inward (earthward) displacement of the magnetopause.

The solar wind pressure pulses seen from the Wind spacecraft at $\sim 0200$ - 1200 UT on November 8, 2000 were also observed later by MGF magnetometer (Kokubun et al. 1994) and the Comprehensive Plasma Instrument (CPI) solar wind analyzer (Frank et al. 1994) on-board the Geotail spacecraft, which was located at $\sim(11.0,-27.4,5.8) R_{E}$ at $0200 \mathrm{UT}$ and $(15.9,-22.4,13.6) R_{E}$ at $1200 \mathrm{UT}$. Geotail encountered a number of bow shock crossings during this time period, which can be seen in the IMF $B_{z}$ data in Fig. 1a as shaded regions. Figures $1 \mathrm{~b}$ and $\mathrm{c}$ show the solar wind proton density and dynamic pressure during the occurrence of pressure pulses/magnetic cavities. These solar wind and IMF data have shifted in time to the Earth's subsolar 
(a)

(b)

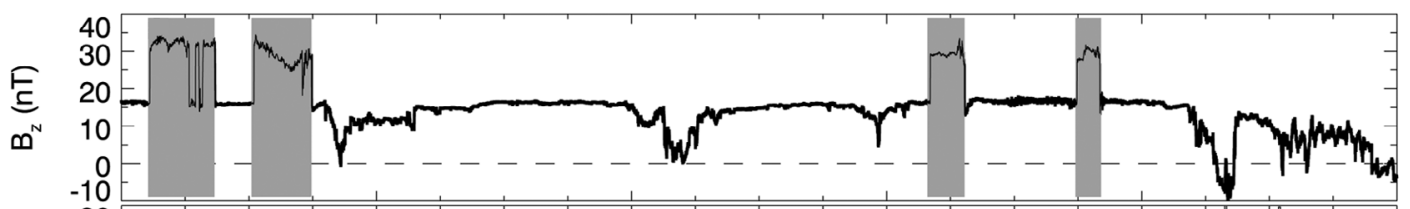

(c)

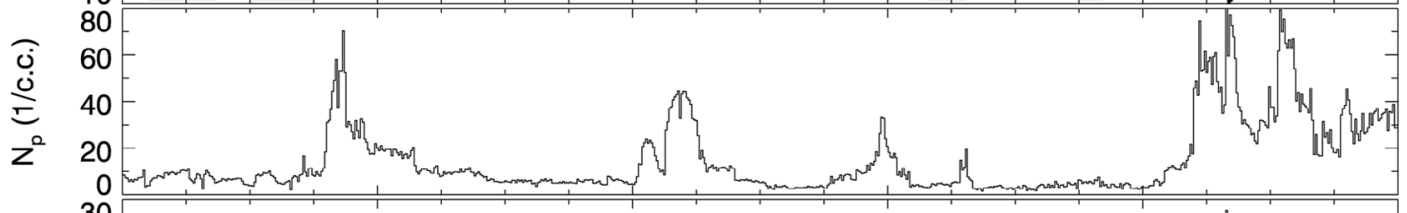

(d)
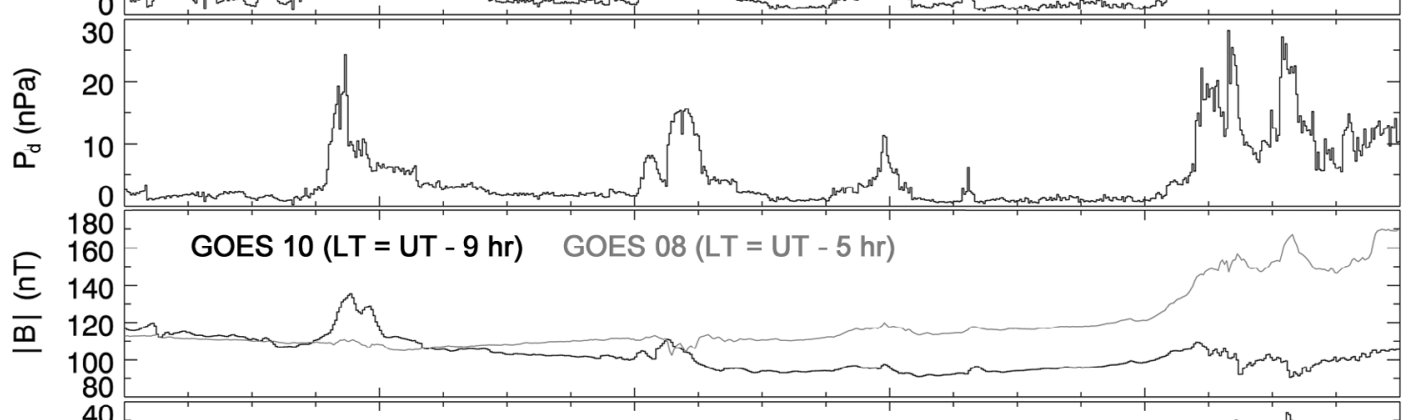

(e)

(f)

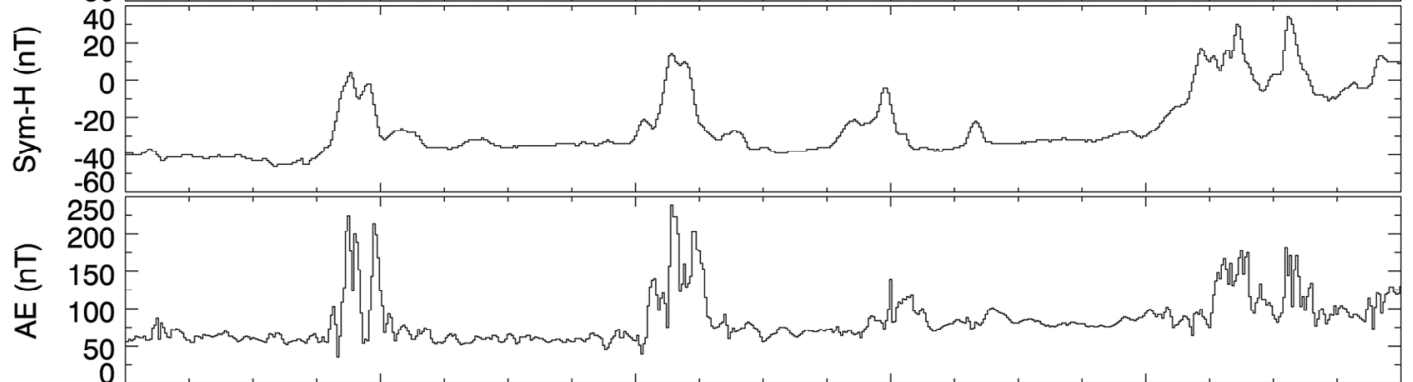

(g)

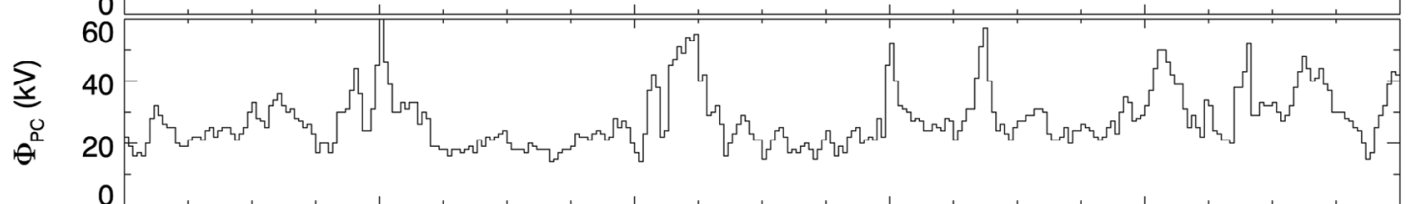

(h)

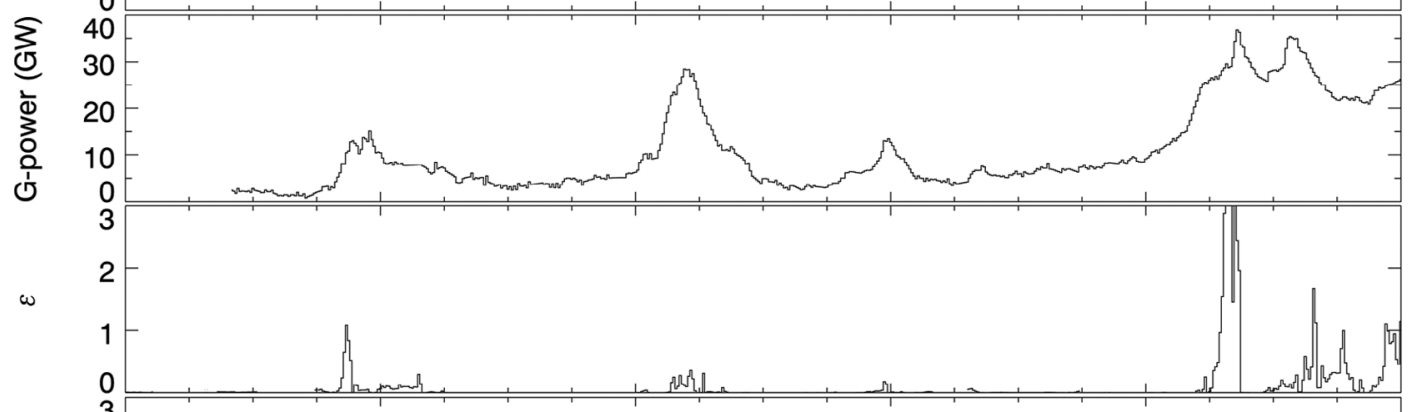

(j)

(k)

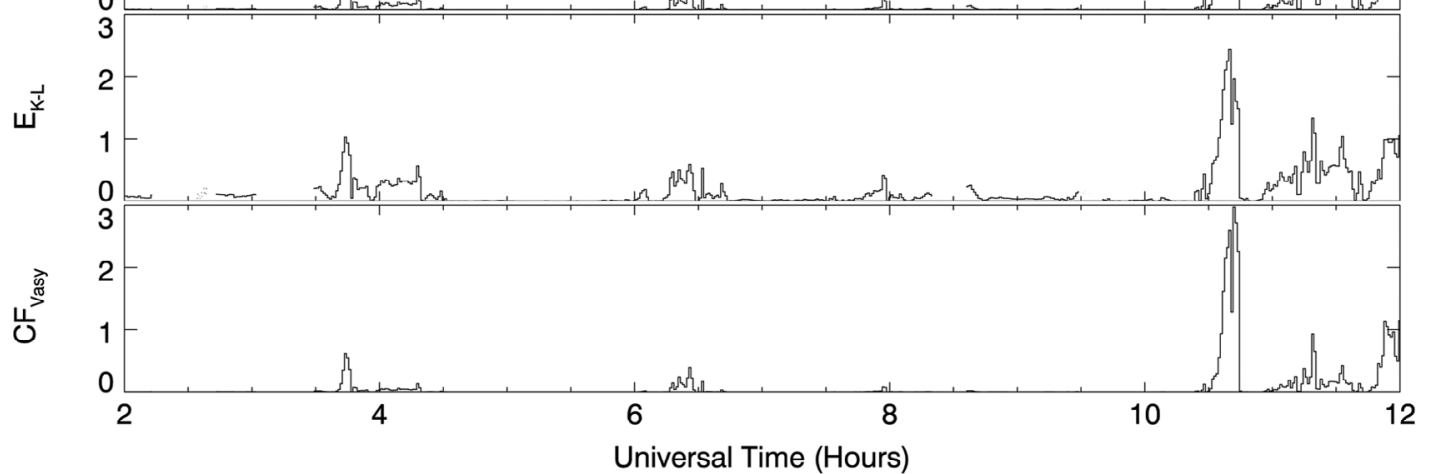

Fig. 1. Stack plots of, from top to bottom, (a) IMF $B_{z}$ component, (b) solar wind proton number density, (c) solar wind dynamic pressure, (d) total magnetic field at GOES 08 (light) and GOES 10 (dark), (e) Sym- $H$ index, (f) $A E$ (dark), $A L$ (light), and $A U$ (light) indices, (g) cross polar-cap potential, $\phi_{p c}$, (h) integrated auroral power $(G A P)$, (i) $\varepsilon=v B^{2} \sin ^{4}\left(\theta_{c} / 2\right)$ (Perrault and Akasofu 1979), (j) $E_{K-L}=v B_{T} \sin ^{2}\left(\theta_{c} / 2\right)($ Kan and Lee 1979), and (k) $C F_{V}=P_{d}^{1 / 6} v B_{T} \sin ^{4}\left(\theta_{c} / 2\right)$ (Vasylinuas 1982) on November 8, 2000 from 0200 to 1200 UT. 
magnetopause by a time lag ( 2 minutes) at which the crosscorrelation coefficient between the dynamic pressure and the $S y m-H$ index (plotted in Fig. 1e) maximizes. The IMF was large in magnitude ( $20 \mathrm{nT})$ and predominately northward for the entire period and its preceding $\sim 14$ hours. A number of large solar wind density pulses ranging from $\sim 20$ to $\sim 80$ c.c. $^{-1}$ were identified and occurred at $\sim 0335, \sim 0600$, $\sim 0730, \sim 0830,1020$, and $\sim 1100 \mathrm{UT}$, respectively. Because the solar wind bulk flow was relatively steady, the solar wind dynamic pressure also showed pulse-like structures. The magnitude of IMF was large ( $20 \mathrm{nT})$ outside the pressure pulses but reduced greatly, especially the dominant $B_{z}$ component inside the pulses. These dynamic pressure pulses/magnetic cavities have a thickness of $\sim 10-20 \mathrm{~min}$ $\left(\sim 40-80 R_{E}\right)$ in the radial direction. Similar features of these pressure pulses/magnetic cavities were also observed earlier by the Advanced Composition Explorer (ACE) satellite (not shown), indicating that they are large-scale phenomena (over $100 R_{E}$ in the transverse direction).

\subsection{IONOSPHERIC RESPONSES}

\subsubsection{High-Latitude Auroral Electrojets}

The auroral electrojet $A E$ index for the 0200 - 1200 UT interval is plotted in Fig. If as a dark line. It is shown that the response of the total auroral electrojets is positive. The intensification of $A E$ occurred concurrently with the arrival of the pressure pulses. Surprisingly, the $A E$ index exceeded $\sim 200 \mathrm{nT}$, a typical small substorm level. Such a prompt enhancement of the auroral electrojets associated with magnetospheric compression has been reported previously by Liou et al. (2004) and is named "compression bays" in against the more familiar negative bays associated with substorms. The eastward, $A U$, and westward, $A L$, electrojet indices are also plotted in Fig. 1f as light traces. In general, both $A U$ and - $A L$ follow nicely with $A E$, except that $A U$ is slightly more intense than $A L$.

\subsubsection{Cross-Polar Cap Potential}

The response of the cross-polar cap potential, $\phi_{p c}$, to the compression of the magnetosphere is shown in Fig. 1g. The cross-polar cap potential is obtained from ionospheric convection measurements from the Super Dual Auroral Radar Network (SuperDARN) radar network (Greenwald et al. 1995). A standard mapping algorithm developed by Ruohoniemi and Baker (1998) is used to assemble and synthesize the individual sets of line-of-sight velocity measurements into a best-fit estimate of the global pattern of plasma convection. The global convection patterns are generated at a cadence of 2 minutes and the corresponding potential drops are plotted in Fig. 1g. It is clearly shown that there is one to one response between the pressure pulses and potential drops.

\subsubsection{Global Auroral Power}

The global ionospheric response to the pressure pulses/ magnetic cavities was also monitored by the Polar ultraviolet imager (UVI) (Torr et al. 1995) in the Northern Hemisphere. During this time interval, UVI was operated in a single-filter (LBHl: 160 - $180 \mathrm{~nm}$ ) and single-integration mode (37 s), thus providing highest temporal resolution auroral images from UVI. Auroral luminosities within this emission band are proportional to the energy flux of typical precipitating auroral electrons (Strickland et al. 1989; Germany et al. 1994). Polar UVI images during this time period have been discussed previously (Liou et al. 2005). To illustrate basic auroral dynamics in a global aspect, we use global auroral power $(G A P)$ and local-time auroral keogram (LAK) (Meng and Liou 2002). The auroral power is derived from the UVI auroral images based on auroral transport modeling result (Germany et al. 1998) and is shown in Fig. 1h. The enhancements of global auroral power were in good one-toone correspondence with the pressure pulses.

Figure 2 shows LAK for the 0300 - 1200 UT period. The auroral brightenings associated with the pressure pulses first occurred on dayside near noon then propagated/extended toward nightside, similar to those reported by Zhou and Tsurutani (1999) for interplanetary shock-induced auroras. Note that intensification of the aurora can be seen to occur at night times at, for example, 0600 and 0800 UT; however, they occur prior to the SI onsets and are not associated with the pressure pulses. It is also important to point out that these nighttime auroral brightenings are not associated with substorms. Actually, the energy deposition for these auroral brightenings is quite small. For example, at 0620 UT, the auroral power in the premidnight sector is only a few gigawatts per local hour sector, which is about one order of magnitude smaller than typical substorm power [see, e.g., Meng and Liou (2002)]. The time difference between the day and night brightening was $2-4 \mathrm{~min}$. The propagation speed of the pressure pulses, estimated from the time and location differences in the first appearance of the pressure pulses time at ACE and Geotail, is $\sim 490 \mathrm{~km} \mathrm{~s}^{-1}$. If we take the subsolar point at 7.2 $R_{E}$ for $P_{d} \sim 20 \mathrm{nPa}$ and $B_{z} \sim 0$ (Shue et al. 1998), the 2 - 4 min day-to-night propagation time would, therefore, correspond approximately to the time it takes for the pressure pulses across the dayside magnetosphere.

\subsection{Magnetospheric Source of Precipitation}

Apparently, compression auroras are caused by enhanced particle precipitation associated with magnetospheric compression. A few past studies have shown that the major particle source for compression auroras in the dawn and dusk sectors has structureless particle precipitations originated from the central plasma sheet for mixed southward and northward fields of the IMF (e.g., Liou et al. 2006). For 


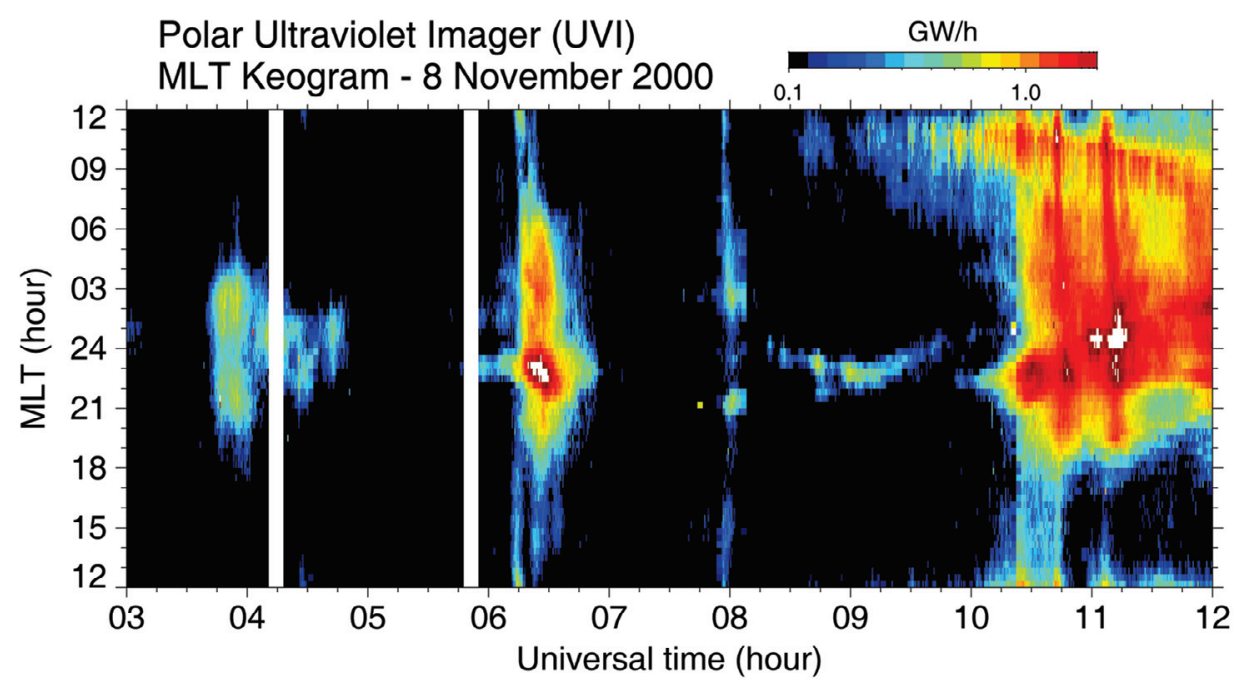

Fig. 2. Magnetic local-time keogram showing auroral power (inferred fro $60^{\circ}$ to $90^{\circ}$ magnetic latitudes) in gigawatt at different hourly sectors on November 8, 2000 for 0200 to 1200 UT. The auroral power is inferred from auroral images in the Lyman-Birge-Hopfield band (160 - $180 \mathrm{~nm}$ ) acquired from the Polar ultraviolet imager.

this event, we have checked particle data from DMSP and found instances that can be used to address this question for purely northward IMF conditions. Figure 3 shows particle spectrograms from DMSP F13 for two consecutive northern polar passes: first (top panel) at 0750 - $0800 \mathrm{UT}$ and next (bottom panel) at 0933 - 0942 UT. The first pass occurred during the impact of the third pressure pulse, whereas the second occurred after the impact. Note that the trajectories of the two DMSP passes are approximately the same, passing the postnoon during the northbound and the prenoon during the southbound. In the postnoon sector, particles are a mixture of low-energy (a couple of hundred $\mathrm{eV}$ ) sheath ions and electrons and high-energy $(>1 \mathrm{keV})$ magnetospheric ions. This region is located at high latitudes $\left(>\sim 75^{\circ} \mathrm{mag}-\right.$ netic latitudes) and most likely maps to the lower-latitude boundary layer (LLBL). In the low-latitude prenoon sector $\left(<\sim 75^{\circ}\right.$ magnetic latitudes), particle spectrum is filled with high-energy, structureless electrons, likely coming from the central plasma sheet (CPS). Comparing the spectra between the two passes, one can see the major difference is the enhancement of CPS precipitation. The energy flux of CPS electron precipitation shows an increase of $\sim 5$ times from $\sim 2 \times 10^{10}$ to exceed $1 \times 10^{11} \mathrm{eV}\left(\mathrm{cm}^{2} \text {-sr-s }\right)^{-1}$. The energy flux of precipitating electrons in the postnoon sector also increased slightly. Overall, the total energy flux is dominated by CPS precipitation during the impact of the third pressure pulse and is likely responsible for the auroral enhancement observed by Polar UVI.

\subsection{Correlation Analysis}

In the previous sections we have demonstrated positive responses of a number of ionospheric parameters to a series of short-duration (10 - $20 \mathrm{~min}$ ) solar wind pressure pulses under extended northward IMF conditions. This result strongly suggests that the solar wind dynamic pressure is the prime driver of these ionospheric perturbations. Indeed, magnetohydrodynamics (MHD) simulations have shown that enhanced field-aligned currents and convection can arise in response to magnetospheric compression during a northward IMF (Fujita et al. 2003). On the other hand, although the IMF was predominantly northward, the $y$-component of the IMF became large and may result in an increase in magnetic field merging (Crooker 1979). In addition, when the solar wind dynamic pressure is high, reconnection could occur at the subsolar magnetopause under northward IMF conditions (Russell et al. 2000). Therefore, one cannot be certain if these pressure pulses are fully accountable for the perturbations in the auroral electrojets, the cross-polar cap potential, and the aurora. To measure the result more quantitatively, we calculate the Pearson productmoment correlation coefficient between a number of solar wind and ionospheric parameters. Specifically, we consider three previously proposed solar wind-magnetosphere coupling functions: $\varepsilon=v B^{2} \sin ^{4}\left(\theta_{c} / 2\right)$ (Perreault and Akasofu 1978), $E_{K-L}=v B_{T} \sin ^{2}\left(\theta_{c} / 2\right)$ (Kan and Lee 1979), and $C F_{V}=$ $P_{d}^{1 / 6} v B_{T} \sin ^{4}\left(\theta_{c} / 2\right)$ (Vasylinuas 1982), where $B_{T}$ and $\theta_{c}\left[=\tan ^{-1}\right.$ $\left.\left(B_{y} / B_{z}\right)\right]$ is the transverse component and the clock angle of the IMF, respectively. The IMF By effect on merging is included in the $\sin ^{2}\left(\theta_{d} / 2\right)$ term to ensure that magnetic field merging does not diminish for nonzero IMF $B_{y}$ during northward IMF conditions. These three coupling functions, after normalized by $B=B_{z}=5 \mathrm{nT}$ and $V=400 \mathrm{~km} \mathrm{~s}^{-1}$ and $P_{d}=$ $1 \mathrm{nPa}$, are plotted in Figs. 1i - k. Note that the solar wind and IMF parameters are based upon Geotail data. Since the solar wind speed did not show significant changes and the IMF 
(a)

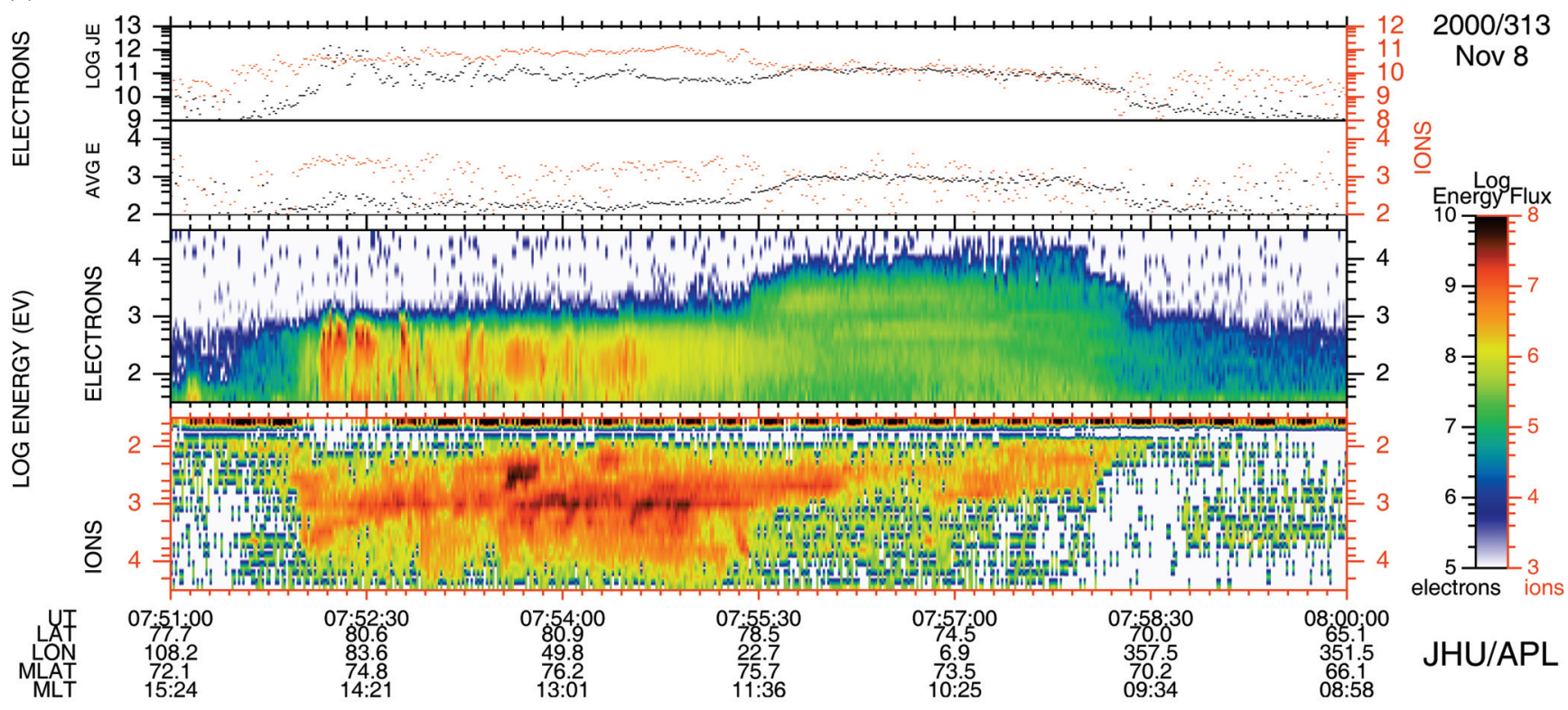

(b)

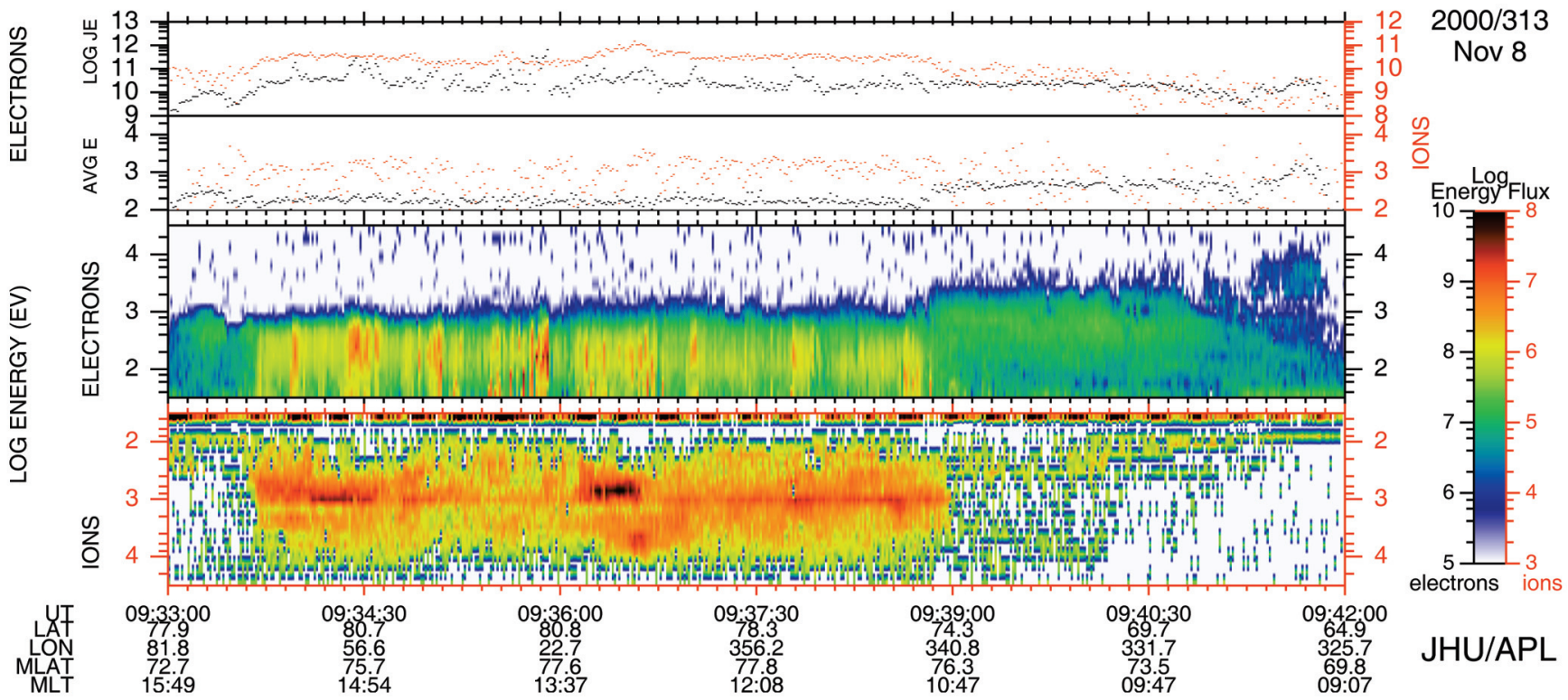

Fig. 3. Auroral particle spectra observed by DMSP F13 (a) during (0751 - 0800 UT) and (b) after (0933 - 0942 UT) a pressure pulse.

magnitude actually showed a decrease associated with these pressure pulses, increases in these coupling functions come mainly from the increase in the IMF clock angle.

Table 1 summarizes the Pearson correlation coefficients. Note that the correlation coefficients listed here represent the maximum values, which are obtained by computing the cross-correlation with various lag times. It shows that all three empirical functions are not well correlated with the all four ionospheric parameters $\left(A E, S y m-H, \phi_{p c}\right.$, and $G A P$ ) for a wide range of lag times considered. The theorized solar wind-magnetosphere coupling function, $\varepsilon$,
(Perreault and Akasofu 1978) ranks the last, with maximum correlation coefficients ranging from $r=0.23$ for the $\varepsilon-\phi_{p c}$ pair to $r=0.43$ for the $\varepsilon$-GAP pair. Another theorized function $C F_{V}$ (Vasyliunas 1982) ranks slightly better, with correlation coefficients ranging from $0.27\left(\phi_{p c}\right)$ to $0.48(\mathrm{Sym}-\mathrm{H})$. The well accepted empirical solar wind electric field $E_{K-L}$ (Kan and Lee 1979) ranks the first among the empirical function group with correlation coefficients ranging from $0.34\left(\phi_{p c}\right)$ and $0.59($ Sym- $H)$. Such a small correlation suggests that dayside merging cannot be accountable for the observed increase in the ionospheric parameters. On the other 
hand, the dynamic pressure is much better correlated with these ionospheric parameters; the largest correlation coefficient comes from the $P_{d}-S y m-H$ pair $(r=0.91)$, which is followed closely by the $P_{d}-G A P$ pair $(r=0.90)$. The correlation coefficient for the $P_{d}-A E$ pair is 0.65 and for the $P_{d}-A E$ pair is 0.66 . Note that the solar wind dynamic pres- sure correlates better with $A U(r=0.66)$ than with $A L(r=$ $0.36)$, indicating the auroral electrojet is convection driven.

In Fig. 4 the lag times for maximum correlation coefficients are generally small (within 10 minutes) for all parameters, indicating a prompt response. Note that the zero lag time for the $P_{d}-S y m-H$ pair, which is consistent with our

Table 1. Correlation coefficients of ionospheric parameters with solar wind parameters and proposed solar wind-magnetosphere coupling functions (coefficients are maximized with time shifted in minutes indicated by numbers inside the parenthesis).

\begin{tabular}{lccccl}
\hline & $\boldsymbol{G A P}$ & $\boldsymbol{S y m}-\boldsymbol{H}$ & $\boldsymbol{A E}$ & $\boldsymbol{\Phi}_{\boldsymbol{p c}}$ & \multicolumn{1}{c}{ References } \\
\hline$v B^{2} \sin ^{4}\left(\theta_{c} / 2\right) l_{0}^{2}$ & 0.43 & 0.42 & 0.34 & 0.23 & Perreault and Akasofu (1978) \\
$P_{d}{ }^{1 / 2} v B_{T} \sin ^{4}\left(\theta_{c} / 2\right)$ & 0.47 & 0.48 & 0.38 & 0.27 & Vasyliunas (1982) \\
$v B_{T} \sin ^{2}\left(\theta_{c} / 2\right)$ & 0.61 & 0.59 & 0.47 & 0.34 & Kan and Lee (1979) \\
$N_{p}$ & 0.89 & 0.87 & 0.66 & 0.43 & \\
$P_{d}$ & 0.90 & 0.91 & 0.65 & 0.45 & \\
\hline
\end{tabular}
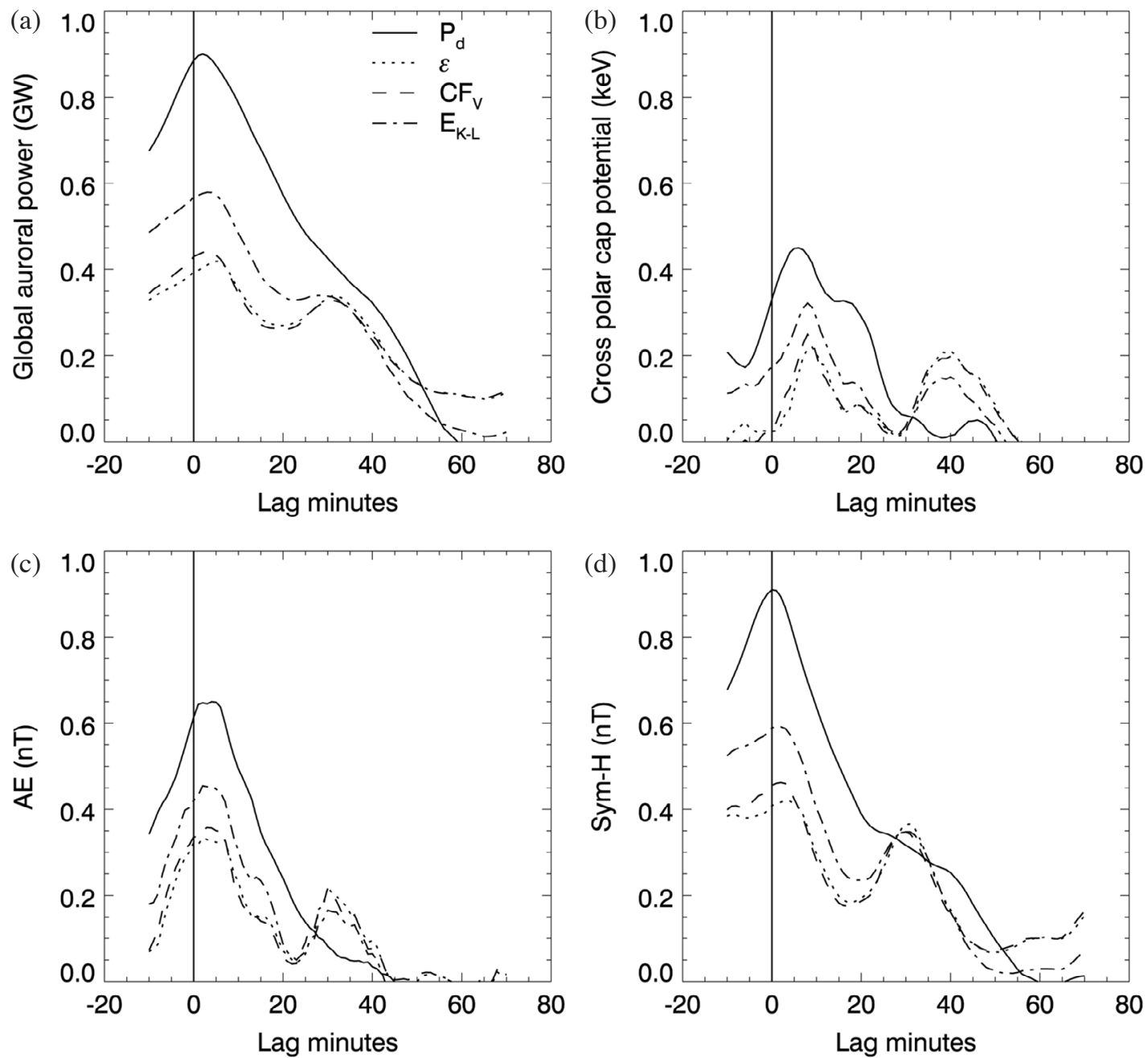

Fig. 4. Cross correlation analysis of (a) global auroral power, (b) cross polar cap potential, (c) the auroral electrojet $A E$ index, and (d) the $S y m-H$ index in response to different solar wind drivers. 
solar wind propagation analysis. The maximum response time is $\sim 2-5$ minutes for the aurora, $\sim 2-8$ minutes for the auroral electrojets, and $6-8$ minutes for the cross polar cap potential. There are secondary peaks in the lag response for all parameters. This is due to the strong response occurring between 1000 and 1200 UT because they disappear if the upper data time limit is set to 1100 UT or earlier.

\subsection{Quantitative Analysis}

To quantify the solar wind dynamic pressure effect, we plot the solar wind dynamic pressure against the four ionospheric parameters and perform a least-squares line fit, assuming a linear response, to each of the parameter-dynamic pressure pair for the entire period of 0330 - 1200 UT. The results are listed below and the linear fits are shown in Figs. 5a - d.

$$
\begin{aligned}
\operatorname{Sym}-H\left(\mathrm{nT}, \sigma^{2}=51.6\right) & =(-36.8 \pm 0.5) \\
+ & (3.0 \pm 0.1) P_{d}(\mathrm{nPa})
\end{aligned}
$$

$A E\left(\mathrm{nT}, \sigma^{2}=583.7\right)=(68.0 \pm 1.5)$

$$
+(3.9 \pm 0.2) P_{d}(\mathrm{nPa})
$$

$$
\begin{aligned}
\phi_{p c}\left(\mathrm{kV}, \sigma^{2}=73.1\right) & =(23.9 \pm 0.5) \\
& +(0.8 \pm 0.1) P_{d}(\mathrm{nPa})
\end{aligned}
$$

$$
\begin{aligned}
\text { GAP }\left(\mathrm{GW}, \sigma^{2}=15.7\right) & =(3.9 \pm 0.3) \\
+ & (1.5 \pm 0.0) P_{d}(\mathrm{nPa})
\end{aligned}
$$

where $\sigma^{2}=\sum\left(y_{o b s}-y_{f i t}\right)^{2} / N$ and $N$ is the total number of measurement points. The constant term for each parameter fit is likely different for different states of the magnetosphere/ionosphere and the slope for each parameter pair represents the dynamic pressure effect on each parameter for northward IMF when contribution from merging is minimal.

Until now, the absolute value of the drivers and responses are used in the linear analysis. The background value of the solar wind dynamic pressure is not removed, which causes clustered data points near the low solar wind pressure in Figs. 5a - d. These background values are likely to affect the linear fit significantly. Without information about the background pressure, we set a threshold from 1 to $5 \mathrm{nPa}$ and recalculate correlation coefficients and found all correlation coefficients are reduced. Figures $5 \mathrm{e}-\mathrm{h}$ show the dynamic pressure in logarithmic scales. It can be seen that the linear relations hold true even at low dynamic pressure values, especially for $S y m-H$ and GAP. On the other hand, it is interesting to see if the responses are associated with the rate of changes in the solar wind dynamic pressure. The result is plotted in Figs. 5i - 1 and is negative.

\section{DISCUSSION}

This event, of a series of large short-duration pressure pulses associated with a magnetic cloud, demonstrated significant enhancements in a number of ionospheric parameters during a prolonged northward IMF. The increase and decrease in the $S y m-H$ (or $D_{s t}$ ) index to the solar wind pressure pulses is well known and is directly related to the increase and decrease in the magnetopause (ChapmanFerraro) currents and the inward (earthward) and outward motion of the magnetopause caused by the impinging pressure pulses. Some previous studies have suggested that $D_{s t}$ is proportional to the square root of the dynamic pressure (e.g., Ogilvie et al. 1968; Siscoe 1968). The contribution of the solar wind dynamic pressure to the $H$-component of the magnetic field at mid-latitude ground stations has been empirically obtained as $D_{s t}=-20+15.8 \times P_{d}^{1 / 2}$ (Burton et al. 1975; Gonzalez et al. 1989). This empirical result is plotted in Figs. 5a and e as a dashed line for a comparison. It clearly shows that a linear fit seems to be better, at least for northward IMF conditions. Note that there is a large difference in the zero intercept between their result and this study result ( 160\%). The large negative constant from this study is likely to be caused by residues of the storm ring currents, as the geomagnetic storm associated with the November magnetic cloud was not fully subsided. As shown in Fig. 1, although the $K_{P}$ index was only 2 but the background $D_{s t}$ was $\sim-40 \mathrm{nT}$ (instead of zero) prior to the arrival of the first pressure pulse.

The auroral electrojet enhancements in response to the pressure pulses are associated with both convection and conductivity increases. The two-event study of Shue and Kamide (2001) demonstrated a positive relationship between the solar wind density and the intensity of the auroral electrojets. They also found that the relationship is more pronounced during a southward IMF. Because the solar wind velocity for their events is relatively unchanged, it is expected that the enhancements of the auroral electrojets may have come from the magnetospheric compression associated with the larger solar wind dynamic pressure. Shue and Kamide (2001) proposed that the enhancements of the auroral electrojets were associated with auroral intensification. Our result not only provides further support for enhancements of auroral electrojets by compression, but also indicates that auroral electrojet enhancements during compression result from enhancements in both conductivity (auroral precipitation) and convection (electric field) in the ionosphere. In addition, our lag-time analysis indicates that both the aurora and the auroral electrojet $A E$ index have a slightly shorter maximum response time $(\sim 2-5 \mathrm{~min})$ than the cross polar cap potential ( $\sim 6-8 \mathrm{~min})$. A detailed analysis of the lag times indicates that the response time for the $G A P-P_{d}$ pair is strongly peaking at $\sim 2 \mathrm{~min}$, while the $A E-P_{d}$ pair has two peaks: one at $\sim 2$ and the other at $\sim 5 \mathrm{~min}$. It is possible that 
the two-peak feature in the $A E-P_{d}$ lag time is caused by two different processes, conductivity and electric field. For example, there are two large $A E$ pulses in response to the first pressure pulse, with the first $A E$ pulse slightly larger than the second one. However, $\phi_{p c}$ was smaller during the first than the second $A E$ pulse. This may be because ionospheric conductivity is larger during the first than the second $A E$ pulse, as suggested by the global power. Therefore, in the cross-correlation analysis, the first peak in $A E$ was probably associated with the conductivity increase, whereas the second peak in $A E$ was probably associated with the electric field increase.

A good linear relationship between the solar wind dynamic pressure and the auroral power is somewhat unexpected. Conclusions from previous reports seem to suggest that the enhancements of aurora are associated with a sudden pressure increase at the shock front; the magnetosphere will have time to respond to a slow pressure increase quasistationary and will not lead to a significant aurora. The present result, on the other hand, indicates that it is the dynamic
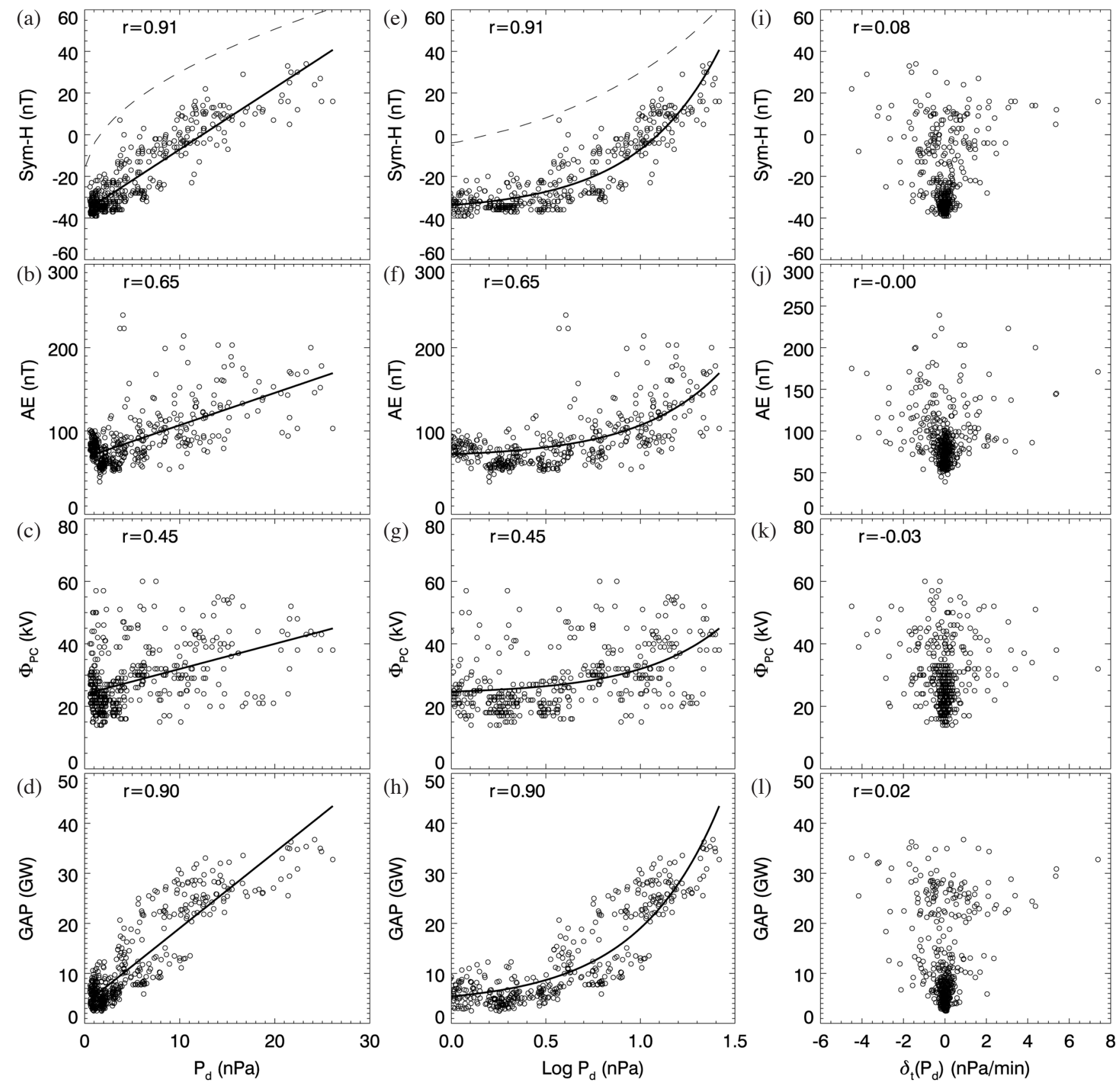

Fig. 5. Least squares fits of (a) Sym-H, (b) $A E$, (c) $\phi_{p c}$, and (d) GAP by the solar wind dynamic pressure (solid straight lines). The dashed curve in (a) is based upon Burton et al. (1975). The fitting results and Pearson correlation coefficients, $r$, are provided at the top of each panel. Panels (e) - (h) and panels (i) - (l) show logarithmic and rate of change in dynamic pressure, respectively. 
pressure but not its change that causes the aurora, at least under northward IMF conditions. Because of the immediate response of the aurora and a good correlation between the auroral power and the solar wind pressure $($ c.c. $=0.90)$, the increase and decrease in auroral power must be closely related to the compression and depression of the magnetosphere. Energy spectra of precipitating particles observed by DMSP on one oval crossing indicate that the major form of the auroral enhancements seen by Polar UVI is of diffuse type originating from the central plasma sheet. Previous studies from a limited number of satellite oval crossings also concluded with the same particle source from CPS (e.g., Zhou et al. 2003, 2009; Liou et al. 2006, 2007). Therefore, diffuse auroras are likely the dominant auroral form during magnetospheric compression. Particle pitch angle scattering by wave-particle interaction (e.g., Zhou and Tsurutani 1999; Tsurutani et al. 2001) and/or changes in magnetic mirror ratio (Liou et al. 2006) are probably two main causes of enhanced particle precipitation without acceleration. However, the marginally trapped CPS electrons in a flux tube can be emptied within a few seconds by the loss cone increase; therefore, it requires plasma waves that pitch-angle scatter more deeply trapped electrons into the loss cone to sustain the auroral emission during stable compression. The plasma wave(s) that may be responsible for the scattering process has not been identified, nor has the mirror ratio mechanism been directly proved. Future studies in these two issues will help with a further understanding of the auroral process associated with dynamic pressure.

The sudden increase in the cross-polar cap potential drop during northward IMF periods was probably mainly driven by the pressure pulses as suggested by our correlative study. The electrical potential across the polar cap is controlled mainly by the solar wind electric field and a number of statistical studies have related the cross-polar cap potential drop to the IMF (Wygant et al. 1983) and the solar wind electric field (e.g., Reiff and Luhmann 1986; Boyle et al. 1997; Eriksson et al. 2000). Effects from the solar wind density/dynamic pressure were generally considered insignificant. Hairston et al. (1999) analyzed drift-meter data taken from the DMSP spacecraft during the January 1997 CME/MC event and found a surprisingly large crosspolar cap potential drop $\left(\phi_{p c}=235 \mathrm{kV}\right)$. They attributed the unusual large $\phi_{p c}$ to a density/pressure pulse, although it is not clear if the density/pressure pulse is a direct cause of the large $\phi_{p c}$ increase because the IMF had been strongly southward $\left(B_{z} \sim-10 \mathrm{nT}\right)$ for many hours. Toward the end of the $\mathrm{CME} / \mathrm{MC}$ event, the IMF rotated slowly into northward. A large density/pressure pulse was observed and resulted in only a small increase $(\sim 10 \mathrm{kV})$ in $\phi_{p c}$ in the hemispheres. Our result not only supports their finding but also indicates a much larger increase in $\phi_{p c}(30-40 \mathrm{kV})$ can occur during a prolonged northward IMF period. The good proximity in the time profile between the solar wind dynamic pressure and the cross polar cap potential drop suggests that the potential drop is driven mainly by the pressure pulses. Using a MHD simulation, Fujita et al. (2003) showed that ionospheric and magnetospheric plasma convection can arise as a result of magnetospheric compression during the second stage of the main impulse phase. According to their explanation, diamagnetic currents behind the compression front will be mode-converted to field-aligned currents and closed in the ionosphere by the curl free Pedersen currents. Their results also support our cross-correlation analysis result of a 6 - 8 min lag-time for the potential drop relative to the pressure pulses.

Viscous convection may play an important role in this event. It has been reported that the polar cap potential decreases slowly after an IMF turns northward and reaches a value between 15 and $20 \mathrm{kV}$ after $\sim 4$ hours of northward IMF (Wygant et al. 1983). Wygant et al. attributed this asymptotic value to a viscous interaction process. Other studies also suggested that impulse energy injection into the magnetosphere/ionosphere during pressure pulse events does not exist after 4 hours of northward IMF ( Du et al. 2011). If this is the case, the observed background transpolar potential seems to suggest that the reverse convection would only contribute to the polar cap potential no more than $20 \mathrm{kV}$ under very large IMF $B_{z}$ conditions $\left(B_{z} \sim 18 \mathrm{nT}\right)$. Inside the density pulse the high solar wind density is expected to produce a large viscous drag at the magnetopause and hence a large convection flow in the magnetosphere and ionosphere. In contrast to the observed short-time scale increase in the potential, however, viscous drags are a longtime process. Therefore, it is not clear how important the viscous drag may have played in this event. Such a question deserves more detailed studies to help understand the interplay among all the possible effects.

\section{SUMMARY AND CONCLUSIONS}

A series of large-scale solar wind dynamic pressure pulses ( $P_{d}$ up to $\sim 80 \mathrm{nPa}$ and $\mathrm{T} \sim 10-20 \mathrm{~min}$ in durations) impinged the Earth's magnetosphere on 8 November 2000 and produced significant geomagnetic disturbances. The arrival of the pressure pulses produced large northward excursions in the ground magnetic field near the equator $(\triangle S y m-H$ $\sim 30-40 \mathrm{nT}$ ). What is unusual to this event is its prolonged northward IMF before and throughout the event which allows a detailed study of the solar wind pressure effect because effects from magnetic field merging are expected to be small. In response to the pressure pulses, the planetary $K_{P}$ index increased from 2 to 5-. A number of ionospheric parameters also showed significant enhancements in oneto-one correspondence with the pressure pulses with little delay. For example, (1) the auroral electrojet inferred by the $A E$ index was intensified $(A E>200 \mathrm{nT})$, (2) the transpolar potential also showed a one-to-one increase to the pressure 
pulses $(\sim 50-60 \mathrm{kV})$, and (3) the northern hemispheric auroral power, inferred from Polar UVI images, also increased significantly $(\sim 30 \mathrm{GW})$, with the brightening first occurring on dayside then nightside. The (linear) response rate to the solar wind dynamic pressure is also calculated as $3.9 \mathrm{nT} / \mathrm{nPa}$ for $A E, 3.0 \mathrm{nT} / \mathrm{nPa}$ for $S y m-H, 1.5 \mathrm{GW} / \mathrm{nPa}$ for $G A P$, and $0.8 \mathrm{kV} / \mathrm{nPa}$ for $\phi_{p c}$.

The analysis of this event demonstrates that dynamic pressure alone can produce significant geomagnetic disturbances. The correlation analysis suggests that these positive ionospheric responses are directly associated with the solar wind dynamic pressure rather than the solar wind electric field. Further studies are required to understand the underlying physical process.

Acknowledgements We wish to thank the two referees for the valuable suggestions, which improve the manuscript considerably. G. Parks is the PI for Polar UVI. The solar wind plasma and IMF data from Wind were provided by K. Ogilvie (PI of SWE) and R. Lepping (PI of MFI), respectively, through NSSDC at NASA Goddard. Geotail IMF data were provided by S. Kokubun (PI of MGF) through DARTS and Geotail solar wind data were courtesy of W. Paterson (PI of CPI). GOES magnetometer data were provided by H. Singer through CDAWeb. The cross polar cap potential was provided by J. M. Ruohoniemi, who is one of the SuperDARN PIs. JHUAPL provided the DMSP particle spectrogram, which is made possible by P. T. Newell and T. Sotirelis. The DMSP SSJ/4 particle detectors were designed and calibrated by Dave Hardy, Fred Rich, and colleagues at AFRL at Hanscom AFB in Boston. The US Air Force has publicly released this data. Most of it was obtained through WDC-A (NOAA) in Boulder, with generous supplements from AFRL. $A E$ and $S y m-H$ indices were provided by the World Data Center for Geomagnetism, Kyoto. $K_{P}$ and $D_{s t}$ indices were obtained from NGDC server at NOAA. This work was supported by NSF grant AGS-0964396 to the Johns Hopkins University Applied Physics Laboratory.

\section{REFERENCES}

Axford, W. I. and C. O. Hines, 1961: A unifying theory of high-latitude geophysical phenomena and geomagnetic storms. Can. J. Phys., 39, 1433-1464, doi: 10.1139/ p61-172. [Link]

Boudouridis, A., E. Zesta, L. R. Lyons, P. C. Anderson, and D. Lummerzheim, 2003: Effect of solar wind pressure pulses on the size and strength of the auroral oval. $J$. Geophys.Res., 108, 8012, doi: 10.1029/2002JA009373. [Link]

Boudouridis, A., E. Zesta, L. R. Lyons, P. C. Anderson, and D. Lummerzheim, 2004: Magnetospheric reconnection driven by solar wind pressure fronts. Ann. Geophys., 22, 1367-1378, doi: 10.5194/angeo-22-1367-20
04. [Link]

Boudouridis, A., E. Zesta, L. R. Lyons, P. C. Anderson, and D. Lummerzheim, 2005: Enhanced solar wind geoeffectiveness after a sudden increase in dynamic pressure during southward IMF orientation. J. Geophys. Res., 110, A05214, doi: 10.1029/2004JA010704. [Link]

Boudouridis, A., L. R. Lyons, E. Zesta, and J. M. Ruohoniemi, 2007: Dayside reconnection enhancement resulting from a solar wind dynamic pressure increase. J. Geophys. Res., 112, A06201, doi: 10.1029/2006JA012141. [Link]

Boyle, C. B., P. H. Reiff, and M. R. Hairston, 1997: Empirical polar cap potentials. J. Geophys. Res., 102, 111125, doi: 10.1029/96JA01742. [Link]

Burton, R. K., R. L. McPherron, C. T. Russell, 1975: An empirical relationship between interplanetary conditions and $D_{s t} . J$. Geophys. Res., 80, 4204-4214, doi: 10.1029/JA080i031p04204. [Link]

Craven, J. D., L. A. Frank, C. T. Russell, E. J. Smith, and R. P. Lepping, 1986: Global auroral responses to magnetospheric compressions by shocks in the solar wind: Two case studies. In: Kamide, Y. and J. A. Slavin (Eds.), Solar Wind Magnetosphere Coupling, 367-380, Terra Scientific, Tokyo.

Crooker, N. U., 1979: Dayside merging and cusp geometry. J. Geophys. Res., 84, 951-959, doi: 10.1029/JA084iA03p00951. [Link]

Du, A. M., B. T. Tsurutani, and W. Sun, 2011: Solar wind energy input during prolonged, intense northward interplanetary magnetic fields: A new coupling function. J. Geophys. Res., 116, A12215, doi: 10.1029/2011JA 016718. [Link]

Dungey, J. W., 1961: Interplanetary magnetic field and the auroral zones. Phys. Rev. Lett., 6, 47-48, doi: 10.1103/ PhysRevLett.6.47. [Link]

Eriksson, S., R. E. Ergun, C. W. Carlson, and W. Peria, 2000: The cross-polar potential drop and its correlation to the solar wind. J. Geophys. Res., 105, 18639-18653, doi: 10.1029/2000JA900033. [Link]

Frank, L. A., K. L. Ackerson, W. R. Paterson, J. A. Lee, M. R. English, and G. L. Pickett, 1994: The comprehensive plasma instrumentation (CPI) for the Geotail spacecraft. J. Geomagn. Geoelectr., 46, 23-37.

Fujita, S., T. Tanaka, T. Kikuchi, K. Fujimoto, and M. Itonaga, 2003: A numerical simulation of the geomagnetic sudden commencement: 2. Plasma processes in the main impulse. J. Geophys. Res., 108, 1417, doi: 10.10 29/2002JA009763. [Link]

Germany, G. A., M. R. Torr, D. G. Torr, and P. G. Richards, 1994: Use of FUV auroral emissions as diagnostic indicators. J. Geophys. Res., 99, 383-388, doi: 10.1029/ 93JA02357. [Link]

Germany, G. A., J. F. Spann, G. K. Parks, M. J. Brittnacher, R. Elsen, L. Chen, D. Lummerzheim, and M. H. Rees, 
1998: Auroral observations from the Polar Ultraviolet Imager (UVI). In: Horwitz, J., D. Gallagher, and W. Peterson (Eds.), Geospace Mass and Energy Flow: Results from the International Solar-Terrestrial Physics Program, Geophysical Monograph Series, 104, 149160, AGU, Washington, DC.

Gonzalez, W. D., B. T. Tsurutani, A. L. C. Gonzalez, E. J. Smith, F. Tang, and S.-I. Akasofu, 1989: Solar windmagnetosphere coupling during intense magnetic storms (1978-1979). J. Geophys. Res., 94, 8835-8851, doi: 10.1029/JA094iA07p08835. [Link]

Greenwald, R. A., W. A. Bristow, G. J. Sofko, C. Senior, J.-C. Cerisier, and A. Szabo, 1995: Super dual auroral radar network radar imaging of dayside high-latitude convection under northward interplanetary magnetic field: Toward resolving the distorted two-cell versus multicell controversy. J. Geophys. Res., 100, 1966119674, doi: 10.1029/95JA01215. [Link]

Hairston, M. R. and D. R. Weimer and R. A. Heelis and F. Rich, 1999: Analysis of the ionospheric cross polar cap potential drop and electrostatic potential distribution patterns during the January 1997 CME event using DMSP data. J. Atmos. Sol.-Terr. Phys., 61, 195-206, doi: 10.1016/S1364-6826(98)00128-X. [Link]

Kan, J. R. and L. C. Lee, 1979: Energy coupling function and solar wind-magnetosphere dynamo. Geophys. Res. Lett., 6, 577-580, doi: 10.1029/GL006i007p00577.[Link]

Kokubun, S., T. Yamamoto, M. H. Acuna, K. Hayashi, K. Shiokawa, and H. Kawano, 1994: The geotail magnetic field experiment. J. Geomagn. Geoelectr., 46, 7-21.

Lepping, R. P., M. H. Acũna, L.F. Burlaga, W. M. Farrell, J. A. Slavin, K. H. Schatten, F. Mariani, N. F. Ness, F. M. Neubauer, Y. C. Whang, J. B. Byrnes, R. S. Kennon, P. V. Panetta, J. Scheifele, and E. M. Worley, 1995: The wind magnetic field investigation. Space Sci. Rev., 71, 207-229, doi: 10.1007/BF00751330. [Link]

Liou, K., P. T. Newell, C.-I. Meng, M. Brittnacher, and G. Parks, 1998: Characteristics of the solar wind controlled auroral emissions. J. Geophys. Res., 103, 1754317557, doi: 10.1029/98JA01388. [Link]

Liou, K., P. T. Newell, C.-I. Meng, C. C. Wu, R. P. Lepping, 2003: Investigation of external triggering of substorms with Polar ultraviolet imager observations. J. Geophys. Res., 108, 1364, doi: 10.1029/2003JA009984. [Link]

Liou, K., P. T. Newell, C.-I. Meng, C. C. Wu, and R. P. Lepping, 2004: On the relationship between shock-induced polar magnetic bays and solar wind parameters. J. Geophys. Res., 109, doi: 10.1029/2004JA010400. [Link]

Liou, K., J. M. Ruohoniemi, P. T. Newell, R. Greenwald, C.-I. Meng, and M. R. Hairston, 2005: Observations of ionospheric plasma flows within theta auroras. J. Geophys. Res., 110, A03303, doi: 10.1029/2004JA010735. [Link]
Liou, K., P. T. Newell, T. Sotirelis, and C.-I. Meng, 2006: Global auroral response to negative pressure impulses. Geophys. Res. Lett., 33, L11103, doi: 10.1029/2006GL 025933. [Link]

Liou, K., P. T. Newell, J.-H. Shue, C. I. Meng, Y. Miyashita, H. Kojima, and H. Matsumoto, 2007: "Compression aurora": Particle precipitation driven by long-duration high solar wind ram pressure. J. Geophys. Res., 112, A11216, doi: 10.1029/2007JA012443. [Link]

Meng, C.-I. and K. Liou, 2002: Global auroral power as an index for geospace disturbances. Geophys. Res. Lett., 29, 41-1-41-4, doi: 10.1029/2001GL013902. [Link]

Newell, P. T., T. Sotirelis, K. Liou, C.-I. Meng, and F. J. Rich, 2007: A nearly universal solar wind-magnetosphere coupling function inferred from 10 magnetospheric state variables. J. Geophys. Res., 112, A01206, doi: 10.1029/2006JA012015. [Link]

Nieves-Chinchilla, T. and A. F. Viñas, 2008: Solar wind electron distribution functions inside magnetic clouds. J. Geophys. Res., 113, A02105, doi: 10.1029/2007JA 012703. [Link]

Ogilvie, K. W., L. F. Burlaga, and T. D. Wilkerson, 1968: Plasma observations on Explorer 34. J. Geophys. Res., 73, 6809-6824, doi: 10.1029/JA073i021p06809. [Link]

Ogilvie, K. W., D. J. Chornay, R. J. Fritzenreiter, F. Hunsaker, J. Keller, J. Lobell, G. Miller, J. D. Scudder, E. C. Sittler Jr., R. B. Torbert, D. Bodet, G. Needell, A. J. Lazarus, J. T. Steinberg, J. H. Tappan, A. Mavretic, and E. Gergin, 1995: SWE, a comprehensive plasma instrument for the WIND spacecraft. Space Sci. Rev., 71, 55-77, doi: 10.1007/BF00751326. [Link]

Perreault, P. and S.-I. Akasofu, 1978: A study of geomagnetic storms. Geophys. J. R. Astr. Soc., 54, 547-573, doi: 10.1111/j.1365-246X.1978.tb05494.x. [Link]

Reiff, P. H. and J. G. Luhmann, 1986: Solar wind control of the polar cap potential. In: Kamide, Y. and J. A. Slavin (Eds.), Solar Wind-Magnetosphere Coupling, 453, Terra Sci, Tokyo.

Ruohoniemi, J. M and K. B. Baker, 1998: Large-scale imaging of high-latitude convection with Super Dual Auroral Radar Network HF radar observations. J. Geophys. Res., 103, 20797-20811, doi: 10.1029/98JA012 88. [Link]

Russell, C. T., G. Le, and S. M. Petrinec, 2000: Cusp observations of high- and low-latitude reconnection for northward IMF: An alternate view. J. Geophys. Res., 105, 5489-5495, doi: 10.1029/1999JA900489. [Link]

Shue, J. H. and Y. Kamide, 2001: Effects of solar wind density on auroral electrojets. Geophys. Res. Lett., 28, 2181-2184, doi: 10.1029/2000GL012858. [Link]

Shue, J. H., P. Song, C. T. Russell, J. T. Steinberg, J. K. Chao, G. Zastenker, O. L. Vaisberg, S. Kokubun, H. J. Singer, T. R. Detman, and H. Kawano, 1998: Magne- 
topause location under extreme solar wind conditions. J. Geophys. Res., 103, 17691-17700, doi: 10.1029/98 JA01103. [Link]

Siscoe, G. L., V. Formisano, and A. J. Lazarus, 1968: Relation between geomagnetic sudden impulses and solar wind pressure changes - An experimental investigation. J. Geophys. Res., 73, 4869-4874, doi: 10.1029/JA073i 015p04869. [Link]

Spann, J. F., M. Brittnacher, R. Elsen, G. A. Germany, and G. K. Parks, 1998: Initial response and complex polar CAP structures of the aurora in response to the January 10, 1997 magnetic cloud. Geophys. Res. Lett., 25, 2577-2580, doi: 10.1029/98GL00647. [Link]

Strickland, D. J., R. R. Meier, J. H. Hecht, and A. B. Christensen, 1989: Deducing composition and incident electron spectra from ground-based auroral optical measurements: Theory and model results. J. Geophys. Res., 94, 13527-13539, doi: 10.1029/JA094iA10p135 27. [Link]

Torr, M. R., D. G. Torr, M. Zukic, R. B. Johnson, J. Ajello, P. Banks, K. Clark, K. Cole, C. Keffer, G. Parks, B. Tsurutani, and J. Spann, 1995: A far ultraviolet imager for the International Solar-Terrestrial Physics Mission. Space Sci. Rev., 71, 329-383, doi: 10.1007/BF007513 35. [Link]

Tsurutani, B. T. and W. D. Gonzalez, 1995: The efficiency of "viscous interaction" between the solar wind and the magnetosphere during intense northward IMF events. Geophys. Res. Lett., 22, 663-666, doi: 10.1029/95GL 00205. [Link]

Tsurutani, B.T., X.-Y. Zhou, V. M. Vasyliunas, G. Haerendel, J. K. Arballo, and G. S. Lakhina, 2001: Interplane- tary shocks, magnetopause boundary layers and dayside auroras: The importance of a very small magnetospheric region. Surv. Geophys., 22, 101-130, doi: 10.1023/ A:1012952414384. [Link]

Vasyliunas, V. M., J. R. Kan, G. L. Siscoe, S.-I. Akasofu, 1982: Scaling relations governing magnetospheric energy transfer. Planet. Space Sci., 30, 359-365, doi: 10. 1016/0032-0633(82)90041-1. [Link]

Wygant, J. R., R. B. Torbert, and F. S. Mozer, 1983: Comparison of S3-3 polar cap potential drops with the interplanetary magnetic field and models of magnetopause reconnection. J. Geophys. Res., 88, 5727-5735, doi: 10.1029/JA088iA07p05727. [Link]

Zhou, X. and B. T. Tsurutani, 1999: Rapid intensification and propagation of the dayside aurora: Large scale interplanetary pressure pulses (fast shocks). Geophys. Res. Lett., 26, 1097-1100, doi: 10.1029/1999GL9001 73. [Link]

Zhou, X. and B. T. Tsurutani, 2001: Interplanetary shock triggering of nightside geomagnetic activity: Substorms, pseudobreakups, and quiescent events. J. Geophys. Res., 106, 18957-18967, doi: 10.1029/2000JA00 3028. [Link]

Zhou, X., R. J. Strangeway, P. C. Anderson, D. G. Sibeck, B. T. Tsurutani, G. Haerendel, H. U. Frey, and J. K. Arballo, 2003: Shock aurora: FAST and DMSP observations. J. Geophys. Res., 108, 8019, doi: 10.1029/2002JA009701. [Link]

Zhou, X.-Y., K. Fukui, H. C. Carlson, J. I. Moen, and R. J. Strangeway, 2009: Shock aurora: Ground-based imager observations. J. Geophys. Res., 114, A12216, doi: 10.1029/2009JA014186. [Link] 